\title{
Transdisciplinaridade e educação comunitária: rendas de bilros, rendeiras e bem viver
}

Rosamaria de Medeiros Arnt*

\section{Resumo}

Este artigo apresenta a educação comunitária a partir de uma experiência vivida (vívida) e inacabada, com 42 rendeiras de bilros de Águas Belas, povoado no litoral cearense. As reflexões e análises são tecidas a partir da transdisciplinaridade e de princípios da docência transdisciplinar. A temática da formação pauta-se no bem viver e na busca de um estado de humanidade. Ilustrando o processo, descrevo o contexto, que dá a especificidade singular desta educação comunitária. Mescla-se a contação de uma história com o cenário das rendeiras de bilros, unindo-se às perspectivas da economia solidária, e às contemplações sobre a policrise em nossa civilização, e seus impactos nos diálogos e propostas do projeto Faz̧endo Renda Tecendo a Vida, reconhecendo as mulheres artesãs como agentes transformadoras de nossa realidade comum.

Palavras chave: transdisciplinaridade, educação comunitária, bem-viver

\section{Transdisciplinarity and community education: bobbin lace, lacemakers, and well-living}

\section{Abstract}

This article introduces community education from a lived (lively) and unfinished experience, with 42 bobbin lacemakers from Águas Belas, a village on the coast of Ceará. The reflections and analyses are woven from the

Doutora em Educação (PUC/SP), pós-doutorado na Universidade de Barcelona. Membro do grupo de pesquisa ECOTRANSD: Ecologia dos Saberes, Transdisciplinaridade e Educação/UCB e GEPEC: Grupo de Estudos e Pesquisas em Complexidade/UMESP. Coordena as ações da ONG Semente dos Sonhos, no povoado de Águas Belas, litoral cearense, com os projetos Educação para o Bem-viver com jovens e Fazendo Renda, Tecendo a Vida, com rendeiras de bilros. E-mail: rmarnt@gmail.com; Lattes: http://lattes. cnpq.br/6161577718275362 
transdisciplinarity and the principles of transdisciplinary teaching. The matter of formation is based on well-living and the search for a "state of humanity". To illustrate the process, I describe the context, which provides the unique specificity of this community education. Storytelling is mixed with the scenery of the bobbin lacemakers, connecting to the perspectives of the solidarity economy and the contemplations of the policrisis in our civilization and its impact on the dialogues and proposals of the project "Fazendo Renda, Tecendo a Vida" ("Lacemaking, Weaving Life"), acknowledging the craftswomen as change agents of our common reality. Key words: transdisciplinarity, community education, well-living

\section{Transdisciplinariedad y educaciõn comunitária: encaje de bolillos, bolilleras y buen-vivir}

\section{Resumen}

Este artículo presenta un trabajo de Educación Comunitaria a partir de una experiencia vivencial que se realiza con 42 bolilleras -productoras/ fabricantes de encajes de bolillo-, en Aguas Belas, un pueblo ubicado en el litoral cearense. Las reflexiones y análisis, de este trabajo, fueron tejidos a partir de la transdisciplinariedad y de principios de docencia transdisciplinar. La temática de la formación se basa en el "buen vivir" y en la búsqueda de un "estado de humanidad". Ilustrando el proceso, describo el contexto, que le da la especificidad singular a esta experiencia de educación comunitaria. Se entremezcla la historia del lugar con el escenario de las bolilleras uniéndose/ integrándose las perspectivas de la economía solidaria y las contemplaciones sobre la "policrisis" de nuestra civilización y sus impactos en los diálogos y propuestas del Proyecto "Haciendo encajes, tejiendo la vida" en el que se reconoce a las mujeres artesanas como agentes transformadoras de nuestra realidad.

Palabras clave: transdisciplinariedad, educación comunitária, buen vivir 
Caminhar

(Antônio Machado)

Carlos Rodrigues Brandão

Caminhante, não faço o caminho em que eu caminho mas o caminho me faz o seu caminho.

Se olho para trás

não vejo as marcas que eu deixei na trilha.

Mas dentro de mim eu sinto o sinal que a trilha me deixou.

E quando eu chego não chego a parte alguma além do caminho de onde eu vim

Sou contadora de histórias. Nas aulas do curso de Pedagogia, gostava dos olhares curiosos quando chegava com a malinha e o tapete mágico. Saía de cena a professora, entravam o encantamento e o mistério de todos os tempos, as linguagens de todos os homens e de todas as mulheres, as linguagens de todos os seres. Sentia-me imensa, porque em mim se manifestava o sagrado das vidas e imaginações humanas. Nas histórias misturam-se as palavras de quem as escreve com as minhas, que as conto. Gradativamente me abandono e vou me apropriando do que narro. Não faço a história, mas a história me faz ao contá-la. Não faço o caminho em que eu caminho. O caminho é conjuntamente traçado. Ao escrever este texto, olho para trás. Sem querer, conto uma história. Olho estes dois anos de convivência com as rendeiras de Águas Belas, onde vivo. Não presto atenção às marcas nas trilhas. Vejo os sinais que a trilha me deixou. Como o poeta, procuro as marcas que estão impregnadas na realidade que construímos. Como pesquisadora, me lanço no exercício de distinguir as marcas no presente, percebendo-as incorporadas não só em mim. Se há marcas em cada uma de nós, em cada trocado ${ }^{1}$, em cada peça de renda de bilros, que marcas serão? Sim, sinto os

Trocado é um dos pontos da renda de bilros 
sinais que a trilha deixou, vejo a materialidade e sei/sabemos que algo aconteceu e acontece ainda. De quatro rendeiras, hoje somos 42. Para além dos encontros, compartilhamos resultados e há vínculos que se fortalecem. Para além dos encontros, há uma trilha que nos conduz à formação comunitária. O currículo é vivo, mutante, um labirinto. Os passos têm ritmo próprio. Nosso ritmo. Mulheres, rendas de bilros, educação comunitária. Neste tecido, um aprendizado. Neste artigo, um relato. No olhar e na base, além da amorosidade, a complexidade e a transdisciplinaridade.

\section{As rendas e as rendeiras}

Eu canto porque o instante existe

E a minha vida está completa

Não sou alegre nem sou triste:

Sou poeta

(Trecho do poema Motivo, de Cecília Meireles)

Há quem cante. Há quem construa paredes e pontes. Há as que tecem usando munfadas ${ }^{2}$, bilros e linhas. São as rendeiras. Rendeiras de bilros. Elas tecem, porque as rendas existem e nelas existem. Tecem porque as rendas também as tecem.

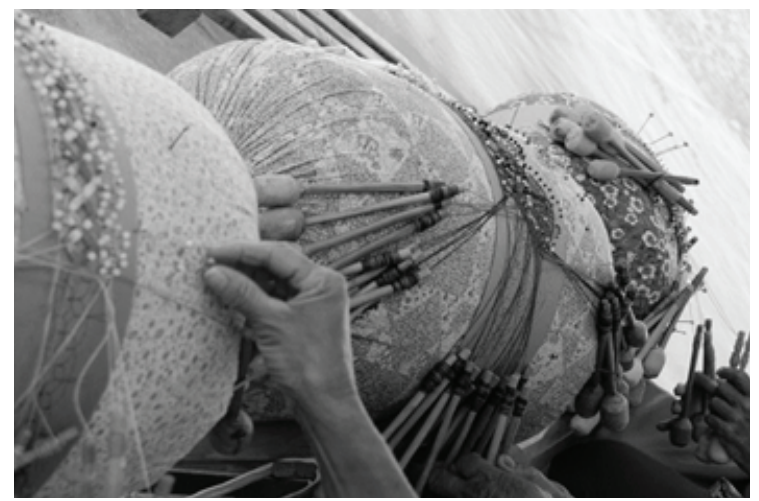

Foto de Ana Arnt

2 Em Águas Belas, mas talvez não só, as almofadas utilizadas para fazer rendas de bilros são chamadas - e escritas - pelas rendeiras como "munfadas" 
Elas criam patrimônio cultural e o patrimônio cultural as cria. São mulheres. Estão nas varandas, nos pátios, nas salas, fazendo rendas como o faziam suas mães e avós.

A renda de bilros é feita utilizando-se como apoio uma almofada, onde fixa-se o "papelão", que contém o modelo da renda. Os bilros são peças de madeira, feitos por artesãos locais, onde enrolamos a linha e com os quais tramamos os fios, tecendo as rendas. Dependendo do desenho e da largura, uma renda pode ter de 6 a 40 pares de bilros, em média. Aqui em Águas Belas, as rendeiras usualmente fazem rendas e bicos em peças de dez metros. A variedade é grande, infinita, se pensarmos nas misturas de cores e no jeito de cada rendeira, tão único.

Mesmo reconhecendo que as rendas não possibilitam um ganho financeiro que seja eficiente no sustento familiar, essas mulheres acreditam e sentem que a vida é mais bonita quando estão em suas munfadas. Há um brilho nos olhos quando falam e explicam o significado de cada ponto, como fazem cantar os bilros e o que é uma renda bem feita.

Contrasta com a beleza da renda, a impossibilidade de gerar renda. Um trocadilho triste, um ganho indigno. Há uma complexidade aqui que não abordaremos, que se explicita na condição da mulher, histórica, estrutural, na desconsideração e desvalorização de seu trabalho, de sua arte.

O desafio que nos acompanha e é a grande temática persistente do projeto Fazendo Renda, Tecendo a Vida e de nosso processo comunitário é a vida para levar, a ser sustentada com as rendas. Consideramos ainda as emergências no fortalecimento dos vínculos, nos afetos, na ocupação de outros espaços, no cruzar das fronteiras da localidade, conquistando paisagens e cenários onde são admiradas e festejadas por sua artesania. 


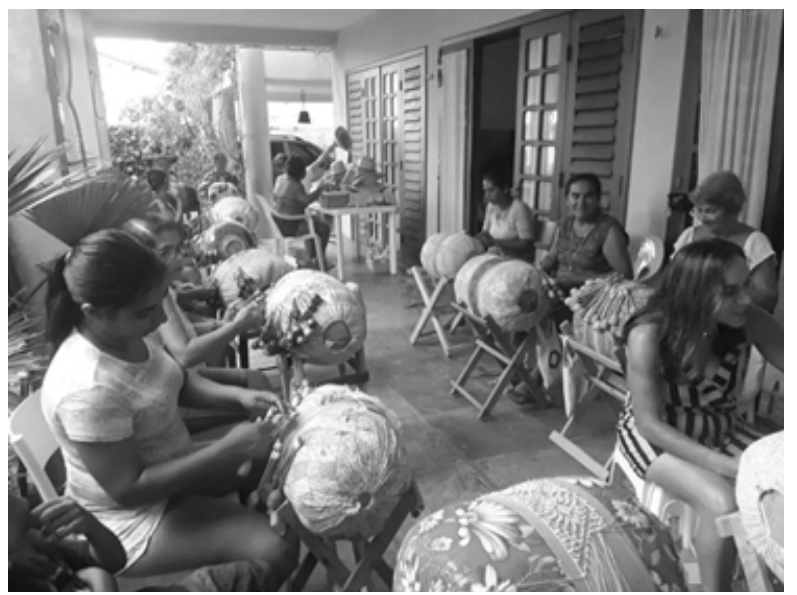

Foto de Alessandra Borges

Temos encontros mensais, quando juntamos nossas rendas e acertamos as contas e sonhamos o porvir. É este o nosso espaço formativo, quando avançamos na compreensão dos princípios da economia solidária, referência para nossas trilhas. Também nesses encontros vamos conjuntamente compreendendo os processos que envolvem nosso projeto, desde a recepção das rendas, ao desenvolvimento de produtos, compras de insumos, envio para as costureiras, cadastramento de rendas e produtos, etiquetagem e comercialização na barraquinha na beira do rio, aqui em Águas Belas e em algumas feiras solidárias que vamos contactando. Aos poucos, a complexidade das atividades vai aumentando, exigindo de nosso labirinto curricular outros corredores a serem trilhados. Nosso movimento e a consolidação do grupo vão gerando emergências. Os encontros já nos pertencem, são parte de nossa rotina, que não existia antes, ao menos não com essa dimensão. As partilhas e os gestos solidários, antes mais facilmente existentes nos pequenos grupos, vão se expandindo em abertura e disponibilidades à medida que vamos nos reconhecendo como um todo.

Talvez possamos dizer, com Cecília Meireles: não somos alegres, não somos tristes. Somos rendeiras. Há nessas mulheres uma 
disposição, verdadeira força poética no enfrentamento às adversidades. O riso é fácil. O encantamento com linhas, papelões, com desenhos de rendas diferentes, uma constante. $\mathrm{E}$ as rendas? Ah! As rendas também são lindas!

\section{Fazendo Renda, Tecendo a Vida}

Trabalho

É uma coisa para alguns homens (Luis Fernando Ocampo, 10 anos)

O objetivo primordial do projeto Fazendo Renda Tecendo a Vida é aumentar o ganho das rendeiras. Ponto. (Mas não só!)

Releio a definição de trabalho dada pelo menino Luis Fernando (apud NARANJO, 2018, p.132). Trabalho é coisa para homens. Para alguns homens. E os outros homens? E as ações das mulheres? E o trabalho das mulheres?

Pois mulheres fazem coisas, fazem coisas com as mãos. Mas não só com as mãos. Mulheres criam coisas, coisas que nem sempre, nem por todos são consideradas trabalho. Pois como mulheres fazem coisas, aprendi com as rendeiras a fazer renda. Aprendi com minhas mãos o tempo das tramas. Minhas mãos me ensinaram que dependendo da largura e do desenho, podemos levar de uma a oito horas para fazer um metro de renda. Pelos valores usualmente pagos às rendeiras, o ganho por hora chega no máximo a um quarto do valor por hora referente ao salário mínimo.

Sim, o objetivo primordial é aumentar o ganho das rendeiras. Mas nunca só, porque na vida é preciso mais do que respirar. É preciso entrelaçar nossas histórias. É preciso entrelaçar o sentido da vida com nossas ações e manifestações.

É preciso pensar um pouco mais e agir um pouco mais. É preciso silenciar e escutar, escutar o grupo que formamos. É preciso criar junto, sentir a força do todo, descobrir que emergências surgem e passam a fazer parte do que somos. É preciso aprofundar nossas raízes em direção aos quatro ventos. É preciso sentir que 
somos porque tudo o mais é, numa tentativa de compreender o significado da Filosofia Ubuntu ${ }^{3}$. É preciso descobrir o que Edgar Morin (2013) nos diz com a expressão estado de humanidade e especialmente o que nos evoca ao dizer que precisamos alcançar este estado. É preciso buscar a relação do estado de humanidade com o trabalho e o rendimento das rendeiras, com nosso projeto.

Alberto Acosta (2016), escritor e economista equatoriano, nos traz a ideia geradora Bem Viver, com significado que tem sua origem entre os povos andinos e amazônicos. Bem Viver se apresenta como uma vida ou um lugar onde a vida é boa, onde há harmonia do ser com a Natureza, consigo mesmo, nas relações, na vivência do bem comum. Não é um conceito pronto, mas indica a necessária construção coletiva de uma nova forma de viver, no respeito aos direitos humanos e aos direitos da Natureza. Mais do que um conceito, é processo com matriz comunitária de povos, tendo por palavras inspiradoras solidariedade e reciprocidade. Segundo Kaká Werá (2020), indígena tapuia, escritor e ambientalista, o Bem Viver, na cultura Guarani, possui 4 características: a vida no contato com a Natureza; o respeito e o vínculo com os ancestrais; o respeito à diversidade; e a inclusão profunda, pois todos somos vida, com a mesma origem.

Paulo Freire (1982, p.38), em trecho retirado de seu contexto - um encontro com trabalhadores no Chile em 1968 - nos ajuda a refletir sobre nosso projeto e sobre as rendeiras: "é necessário que ad-miremos a frase proposta [o papel do trabalhador social no processo de mudança] para, mirando-a de dentro, reconhecer que não deve ser tomada como um mero clichê. A frase em discussão não é um rótulo. Ela é, em si, um problema, um desafio."

Aceitando a frase do menino como um problema e um desafio, como articular a vida de artesãs com o bem viver, com um estado de humanidade? Como ter/ser uma consciência cidadã?

Palavra pertencente aos povos Bantu, da África, pode ser considerada uma filosofia ou um modo de pensar africano, traduzido por uma existência marcada pela convivência harmoniosa com o Outro. Eu sou, porque nós somos. Era assim que Desmond Tutu, religioso sul-africano sintetizava o significado de Ubuntu. (VASCONCELOS, 2017) 
Com perguntas sem respostas, começamos a nos encontrar há dois anos, às quartas-feiras, para fazermos rendas juntas, conjecturando em como viabilizar o trabalho das rendeiras. Éramos quatro pensando em produtos com rendas, que fossem diferentes do que já está consagrado nos espaços de vendas para turistas, pois nossa ideia era - e é - conseguir minimamente triplicar o ganho da artesã, tendo a consciência de que mesmo assim o valor recebido é irrisório.

Aos poucos fomos acolhendo outras rendeiras que chegavam com suas caixinhas cheias de rendas. Tornou-se imprescindível uma organização entre nós, com partilha das possibilidades que encontramos coletivamente, bem como nosso jeito de atuar.

Num processo recursivo e retroativo, concebemos uma jornada que nos concebe. Nenhuma destas 42 rendeiras, entre as quais me incluo, sabe como criar um projeto coletivo, que acolha tal número de artesãs, com propósitos como formação cidadã, consolidação do grupo, autogestão, sustentabilidade econômica e social. Aqui os processos são todos nossos. Ainda projeções, ainda utopias, ainda horizontes: sempre distantes, sempre presentes, orientações de passos.

\title{
3. Educação Comunitária e nosso currículo em labirinto
}

\author{
Construirás os labirintos impermanentes \\ que sucessivamente habitarás
}

Todos os dias estarás refazendo o teu desenho. Não te fatigues logo. Tens trabalho para toda a vida.

E nem para o teu sepulcro terás a medida certa.

Somos sempre um pouco menos do que pensávamos

Raramente, um pouco mais.

(Trecho do poema Desenho, de Cecília Meireles)

E teve início então o desenho do labirinto, muitas vezes refeito, muitas vezes percorrido por trilhas que ora não tinham fim, 
ora eram o fim em si mesmas. Todos os dias estarás refazendo o teu desenho. Tens trabalho para toda a vida.

Nenhum caminho é trilhado só. Neste labirinto, vão comigo, além de Paulo Freire, Edgar Morin, eu mesma com meus estudos e pesquisas sobre a docência transdisciplinar, Maria Cândida Moraes, orientadora sempre presente em tudo que faço e crio. Chamo também Carlos Rodrigues Brandão, Alberto Acosta e, nos corredores da Economia Solidária, Paul Singer, Débora Nunes, Marcos Arruda e Luis Razeto. Além dos poetas e poetisas, como Cecília Meireles, Adonis, Manoel de Barros, imprescindíveis à razão.

Carlos Rodrigues Brandão (2003) me ajuda a conceituar a educação comunitária, a partir da educação popular: uma prática social e um trabalho coletivo que vivencia o saber compartilhado, visando uma consciência cidadã. A organização também é compartilhada e o educador contribui com seu próprio saber, "a serviço" de um trabalho comunitário, de uma ação comum, em benefício de todos.

Sou educadora e contribuo com meu próprio saber. Mas sou completamente parte do grupo que se educa, pois sou também educada neste processo. Nestes dois anos do projeto $\mathrm{Fa}$ zendo Renda Tecendo a Vida, as ações vão avançando de forma não linear. Internamente e no processo coletivo, seguimos por caminhos distintos que se encontram, que se fundem em obstáculos tornados paredes, quando retornamos, escolhemos outras alternativas, conscientes ou não. Às vezes, simplesmente paramos. Nada muito drástico. As escolhas são sutis, pairam nos detalhes, já que as diretrizes de ação visando o Bem Viver são também horizonte, sempre à frente.

De qualquer maneira, já temos algumas conquistas. O grupo formado, parcerias conquistadas, que quase nos asseguram uma frágil sustentabilidade, produtos criados com nossas rendas, controles financeiros, processo formativo em andamento. Não te fadigues logo. Há ainda corredores a percorrer. Mas não irás só! 


\subsection{Transdisciplinaridade e os princípios da docência transdisciplinar}

Habitando o labirinto, busco na transdisciplinaridade o fio de Ariadne, que me permita rever caminhos, retornar por corredores sem me perder ou talvez estando perdida, simplesmente seguir. Transdisciplinaridade, para mim, é uma atitude perante a vida, perante o conhecimento, que nos faz articular saberes, para além da compartimentação de disciplinas, reconhecendo que a aprendizagem acontece na inteireza do ser. Sem dúvida há a necessária junção das artes, da ciência, da filosofia e do sagrado. Mas confesso que ao ver a roda de rendeiras, é como se estas definições fossem excessivas e insuficientes. A base, a lógica de toda a ação educativa e de convivência está no que é intangível, desconhecido e incerto. Uma busca em labirintos mesmo: o bem viver, a consciência cidadã e o estado de humanidade. De repente, o labirinto cresce ameaçador. Utopia? Sonho? Fantasia? Sem saber, sem respostas, deixo assim, por enquanto... E vou partir dos princípios da docência transdisciplinar (ARNT, 2007, 2010), tomados simplesmente como pontos de partida, interdependentes, que se relacionam de forma dinâmica, aberta, sem ordem hierárquica, permitindo sempre novos arranjos, incorporando ideias, complementações que surjam dos contextos onde a docência seja exercida: reconhecer o mundo que vivemos; cultivar o tempo de ser; acolher as partes; acolher o todo; criar juntos nossas próprias histórias.

\subsubsection{Reconhecer o mundo em que vivemos}

O primeiro princípio - reconhecer o mundo em que vivemos - aponta para a necessidade do conhecimento disciplinar. Mas para além do conhecimento disciplinar, a consciência de que ele se assenta em uma visão de mundo, uma lógica que nos é própria, a paisagem que habitamos. Paulo Freire nos diz que toda prática educativa envolve uma postura teórica por parte do educador.

Daí que não possa ser o trabalhador social, como educador que é, um técnico friamente neutro. Silenciar sua opção, escondê-la no emaranhado 
de suas técnicas ou disfarçá-la com a proclamação de sua neutralidade não significa na verdade ser neutro mas, ao contrário, trabalhar pela preservação do "status quo". (FREIRE, 1982, p.39)

Edgar Morin (2000), no primeiro dos Sete Saberes necessários à Educação do Futuro, nos lembra que não é só nossa ignorância que nos cega. Também o conhecimento. Não vemos que não vemos. Ao percebermos nossos pontos obscuros, tornam-se naturais os caminhos e descaminhos pelo labirinto. Perceber que "é assim mesmo" nos dá o alívio da incompletude. Conviver com as incertezas, afrouxar os aparentes controles, entendendo a ecologia da ação (MORIN, 2000), segundo a qual, uma ação por nós iniciada escapa de nossas intenções, já não nos pertence, pois pelo jogo das interações têm desdobramentos que nos escapam. Cabem-nos a atenção, a abertura, a flexibilidade, a confiança no grupo. Iniciamos o processo e já não dominamos a continuidade. Os pontos de chegada serão traçados pelas rendeiras, e por todas as circunstâncias que fazem parte do projeto, como as rendas, os produtos que criamos, as costureiras, os pontos de venda e os resultados. Organizar os temas, como tantas vezes fiz num plano de curso é fácil. Começamos, por exemplo, com a formação do grupo; trabalho coletivo; solidariedade e criatividade. Vamos intercalando cuidados com o corpo, na aprendizagem de exercícios de alongamento e vivências que fortaleçam os vínculos entre nós. As noções de cidadania, de comunidade unem-se aos princípios da economia solidária, enquanto vamos experimentando a autogestão, programando mutirões para que todas compreendam as diferentes atividades que fazem parte do projeto. O conhecimento disciplinar não dá conta. O conhecimento individual também não.

\subsubsection{Cultivar o tempo de ser}

Ao pensar e contemplar sobre o mundo que vivemos, como nos preparamos para a vida, para a docência, para um projeto que envolva a educação comunitária, sendo simultaneamente educadora 
e educanda? Entramos no campo do segundo princípio da docência transdisciplinar - cultivar o tempo de ser,

\begin{abstract}
propondo a abertura ao mundo interior, do cuidado conosco mesmos, buscando a clareza de propósitos de nosso próprio ser, do sentido de nossa vida. É através do cultivo do tempo de ser que visamos a ampliação da consciência, com a ampliação de nosso nível de percepção. É no reencontro conosco mesmos, intencionalmente, que podemos transitar pela zona de não-resistência, redimensionando nossa maneira de ser no mundo, agindo no respeito a nós mesmos, dialogando com o outro/sociedade e com o meio/natureza, na tentativa de equilibrar o triângulo da vida. Este diálogo interior é proposto por um gesto de interrupção, por meio da suspensão do automatismo da ação através da reflexão atenta, da consciência de ser, do cultivo da possibilidade de colocar-se por inteiro em tudo o que se faz, numa perspectiva de autoconhecimento e do entendimento de nossa maneira de ser no mundo. (ARNT, 2010, p.109)
\end{abstract}

Como se dá o cultivo do tempo do ser com as rendeiras? Que momentos e vivências serão esses que as farão olhar para si mesmas, em movimento introspectivo? E ao olharem para si, reconhecerem-se sujeitas num mundo em transformação? Mais que isso, reconhecerem-se sujeitas transformadoras da sua realidade social e cultural?

O cultivo do tempo de ser nos ajudará a refazer o desenho, desapegadamente, compreendendo que temos trabalho para toda a vida? E, especialmente, que somos sempre um pouco menos do que pensávamos / raramente, um pouco mais? O cultivo do tempo do ser significa a compreensão incorporada de nossa condição humana, de nossa complexidade. Significa a abertura para a contemplação de nós mesmos e nossas relações. Significa a inteireza para acolher o outro, também em sua multidimensionalidade.

O cultivo ao tempo de ser nos acrescenta leveza com as incertezas dos processos vividos, pois sendo inacabados e aprendentes, estes instantes de parar para respirar e respirar mais devagar ${ }^{4}$; parar para

4 A inspiração deste trecho é do professor e escritor espanhol Jorge Larrosa (2002), em seu artigo Notas sobre a experiência e o saber da experiência, quando descreve o que chama de gesto de interrupção: "A experiência, a 
escutar, - inclusive a nós mesmas -, e escutar mais devagar; parar para sentir, sentir mais devagar a alegria das rendeiras chegando, os sons dos bilros batendo, carregados de ancestralidades; sentir mais devagar e mais profundamente o compromisso assumido, intimamente, com o que faz sentido para nós; curtir mais devagar e mais amorosamente os passos dados, as aprendizagens realizadas e saber que não há problema em sermos só raramente um pouco mais do que pensávamos.

Cultivar o tempo de ser pode significar a pausa em meio ao movimento e o movimento em meio a pausa, sentindo o movimento e a pausa como duas pulsões de vida, da vida que somos.

\subsubsection{Acolher as partes}

O terceiro princípio - acolher as partes - surge da relação partes/todo e da compreensão de que é preciso conhecer as partes para conhecer o todo.

Sentamo-nos sempre em roda. Às vezes rodas menores. Mas as conversas, tradicionalmente, ainda são centralizadas e a educadora - eu - ainda ocupa muito espaço. Cultivar o tempo de ser do outro, cultivar o tempo de ser coletivo gera ansiedades, como se nós tivéssemos que "gerenciar" todos esses tempos. Ah! o aprendizado da fruição, da fluidez, da leveza no ato educativo! A leveza de caminhar pelos corredores do labirinto sem pressa e aproveitando os passos, sentindo-os à medida que são dados. Caminhar sem pressa, perscrutando o caminho. Mas, ao mesmo tempo, lembrar do propósito que nos une... A vida para levar tem suas urgências. Precisamos encontrar diferentes modos para conhecer quem somos, como somos. Já não basta o que nos une - sermos rendeiras.

possibilidade de que algo nos aconteça ou nos toque, requer um gesto de interrupção, um gesto que é quase impossível nos tempos que correm: requer parar para pensar, parar para olhar, parar para escutar, pensar mais devagar, olhar mais devagar, e escutar mais devagar; parar para sentir, sentir mais devagar, demorar-se nos detalhes, suspender a opinião, suspender o juízo, suspender a vontade, suspender o automatismo da ação, cultivar a atenção e a delicadeza, abrir os olhos e os ouvidos, falar sobre o que nos acontece, aprender a lentidão, escutar aos outros, cultivar a arte do encontro, calar muito, ter paciência e dar-se tempo e espaço.”. 
Perguntas como: quais nossas histórias de vida? Como aprendemos a fazer renda? O que significa fazer renda? fazem parte dos registros que vamos tecendo, utilizando inclusive os recursos das tecnologias digitais. Mas há perguntas que aprofundam o significado dos encontros, da união: o que eu faço com a renda? O que a renda faz comigo? O que desejo que a renda faça por mim?

Essas e tantas outras perguntas começam a ser respondidas, enquanto vamos também compreendendo as habilidades de cada uma. No duplo movimento, em direção a quem somos e em direção às que estão conosco neste projeto, mundos também vão se desenhando, em/com múltiplas mãos. Queremos mesmo é nos entender como partes, exercitando a simpatia, a sororidade, reconhecendo o outro como legítimo outro na convivência, como dizem Maturana e Varela (1995).

É como seres conscientes que mulheres e homens estão não apenas no mundo, mas com o mundo. Somente homens e mulheres, como seres "abertos", são capazes de realizar a complexa operação de, simultaneamente, transformando o mundo através de sua ação, captar a realidade e expressá-la por meio de sua linguagem criadora. (...) Homens e mulheres, indo além do mero estar no mundo, acrescentam à vida que têm a existência que criam. Existir é, assim, um modo de vida que é próprio ao ser capaz de transformar, de produzir, de decidir, de criar, de recriar, de comunicar-se. (...) Para os seres humanos, como seres da práxis, transformar o mundo, processo em que se transformam também, significa impregná-lo de sua presença criadora, deixando nele as marcas de seu trabalho. (FREIRE, 1982, p.66-8)

Será que cada rendeira percebe as marcas que deixa no mundo com seu trabalho? E que marcas deixa no contexto em que vive, na comunidade, na família? Será que reconhece sua presença criadora? Qual a consciência que temos de nossas possibilidades de transformar nossa própria realidade? O sentimento de impotência frente a questões estruturais pode se consolidar nos levando a possíveis paralisias. Ou pode nos levar a outras opções, para nós inovadoras?

Sim, temos mais perguntas que respostas. E seguimos... 


\subsubsection{Criar circunstâncias para a comunhão}

O quarto princípio - criar circunstâncias para a comunhão - emerge, como o anterior, do princípio do pensamento complexo segundo o qual é necessário conhecer o todo para conhecer as partes. Quais as características de um grupo de rendeiras, moradoras em uma pequena localidade de pescadores, com aproximadamente 600 habitantes, à beira de um rio, no interior do Ceará? Que realidade social e cultural habitamos?

Por mais que eu busque e encontre respostas a estas perguntas, são apenas as minhas respostas e, com certeza, não as mais importantes. Em outros contextos, comentando este princípio, ressaltava a necessidade da observação para entender as peculiaridades de cada grupo. Percebia as diferenças, por exemplo, a cada atividade ou vivência propostas, nas diversas turmas do curso de Pedagogia. E ia comparando, entendendo como reagiam, como se configuravam as alunas nos grupos e como alguns projetos em uma sala de aula resultavam em mais união, em criatividade ampliada e, em outras, tornavam-se problemáticos, gerando conflitos que não eram superados ou não no tempo da disciplina. Aqui as questões são outras. As diferenças não são facilmente transpostas. A complexidade das tramas não é facilmente compreendida. Edgar Morin (2000, p.94) no Ensinar a Compreensão afirma:

O axioma "quanto mais próximos estamos, melhor compreendemos", é apenas uma verdade relativa à qual se pode opor o axioma contrário "quanto mais estamos próximos, menos compreendemos”, já que a proximidade pode alimentar mal-entendidos, ciúmes, agressividades, mesmo nos meios aparentemente mais evoluídos intelectualmente.

Se a compreensão intelectual passa pela explicação, a compreensão humana vai além. Percebemos o outro e nos identificamos ou não. E continua Morin (2000, p.95): "sempre intersubjetiva, a compreensão pede abertura, simpatia e generosidade". E há obstáculos, como os mal-entendidos, os ruídos e a polissemia. Morin ainda ressalta a ignorância dos ritos e costumes do outro, e em nos- 
so caso, de uma comunidade inteira. Há valores envolvidos, há a fixação em determinados pontos de vista, em estruturas mentais que constituem nosso cenário individual e muitas vezes nos impedem de compreender o que para o outro provavelmente é relativamente simples. Os diálogos tornam-se imprescindíveis, com a escuta atenta, sensível. O fazer junto, ao longo do tempo, no entanto, parece que vai facilitando este "colocar-se no lugar do outro", vendo o mundo pelos seus olhos. Ao longo destes dois anos, na convivência em ambiente amoroso, observando o passar do tempo e o que acontece com meu olhar para esta realidade, redimensiono mais e mais o que seria a compreensão humana do espaço que habito. Sem dúvida, a amizade, a crença do projeto que abraçamos juntas são ligas importantes. O fortalecimento dos vínculos vai nos proporcionando uma cumplicidade, uma intimidade, ampliando os graus de liberdade no que é dito, no que é silenciado. Os processos de compreensão humana têm seu tempo. $\mathrm{O}$ fazer junto, criar histórias próprias, que nos pertençam, não sei se abreviam este tempo, mas com certeza fazem com que ele passe de maneira prazerosa, consolidando processos e projetos comuns.

\subsubsection{Criar juntas nossas próprias histórias}

O quinto princípio - criar juntas nossas próprias histórias -, vem mesmo na direção de, conhecendo mais e mais o todo que formamos, ousarmos a ação transformadora do/no mundo, como diz Paulo Freire. As emergências surgem nestas histórias, nas alternativas impensadas que despontam enquanto juntas vamos tecendo a trama das rendas e da convivência. Os processos são vivos e devem ser cuidadosos, para incluir a todas, com suas pluralidades e diversidades. A metáfora que utilizo neste princípio é a da dança conjunta, que requer acolhimento e entrega, na busca da harmonia, da beleza, numa coreografia que não é concebida previamente, mas vai sendo constantemente criada e recriada, tendo por ritmo de fundo o que tem nos movido: o Bem Viver, a consciência cidadã, solidária, o estado de humanidade. 


\section{Práxis: a história que queremos criar}

Vela adivinha do futuro

Que tenho que temo o caminho curto?

Adonis

Voltamos às questões: como articular a vida de artesãs com o bem viver, com um estado de humanidade? Como ter/ser uma consciência cidadã?

Não são caminhos curtos. Mas t-alvez não haja, mesmo, caminhos curtos.

Concordamos com Edgar Morin (2013) ao afirmar que estamos vivendo uma policrise, pelas dimensões sociais, políticas, econômicas, culturais, ambientais que identificamos. Luis Razeto (2016), professor e pesquisador chileno, com obra que aborda a crise da civilização moderna e nos apresenta a necessidade de criação de uma nova civilização, analisa a crise sistêmica, especialmente pelo esgotamento da capacidade de inclusão e integração de coletividades, comunidades, povos. Afinal, mais pessoas e grupos sociais vêm sendo expulsos da ordem econômica, sendo também alienados ou expulsos da ordem política, distanciando-se também da ordem cultural. A incapacidade de satisfação das necessidades básicas de grupos sociais cada vez mais numerosos, a perda de credibilidade dos sistemas de representação política e a falta de respostas ou alternativas vindas das ciências sociais, econômicas e políticas são mostras da complexidade da desarticulação que presenciamos (RAZETO, 2016). Compreendendo que nenhum sistema se autodestrói subitamente para que outro emerja, vivenciamos um momento em que não sabemos ou não temos o desenho de uma outra realidade. Apenas, percebemos a falência do sistema atual. Paul Singer (2002, p.10) diz que precisamos entender que a desigualdade não é natural e a competição generalizada tampouco o é. Luis Razeto (2016, p.4) sugere alternativas: 
Por um lado, adotar medidas de ordem defensiva: proteger-nos, evitar a deterioração econômica, política e cultural com seus processos de exclusão social que possam nos afetar demasiadamente nos impedindo de gerar iniciativas de uma nova civilização.

Por outro lado, implantar processos proativos: desenvolver iniciativas criativas, autônomas e solidárias nas quais vamos experimentando e fortalecendo os modos de viver correspondentes a uma civilização superior a que está em crise. [tradução livre da autora]

Estas medidas, ainda segundo o autor, se referem a um nível micro, porque não conseguimos atuar no nível macroestrutural. Uma mudança na inclusão e em condições favoráveis de vida torna-se perceptível quando todas as pessoas sejam ou tenham a possibilidade real e efetiva de serem empresárias, proprietárias ou trabalhadoras, governantes e dirigentes, intelectuais, participantes da produção de conhecimento social ou criadoras de cultura, de acordo com seus desejos.

São processos de longa duração, nos quais convergem e se complementam programas de educação e formação, com iniciativas experimentais, comunitariamente implementadas, que implicam aprendizagens e desenvolvimento de capacidades pessoais e de grupo de empreendedorismo e gestão econômica, de mobilização e participação política e de desenvolvimento intelectual e cultural. (RAZETO, 2016, p.5 - tradução livre da autora)

Embora tais pensamentos possam nos soar desalentadores, há movimentos nascentes, grupos comunitários agindo localmente, pensando (ou tentando pensar) globalmente. Encontramos, por exemplo, universidades com projetos extensionistas nesse sentido, nas chamadas "incubações" de empreendimentos de economia solidária (NUNES, 2009). Uma rede vai se formando e já temos estudos e pesquisas que nos fornecem diretrizes para pensarmos projetos também neste sentido.

Que histórias podemos criar que propiciem a inclusão, o bem viver, a consciência cidadã? Pois não se trata somente de estudar sobre temas importantes em si mesmos. Trata-se de uma vida a viver em consonância com esses valores. Retorno ao desenho do 
labirinto, à necessidade de refazer, recriar. Nada temos a perder. No compromisso com a realidade social local, com o grupo que formamos, há apoios, parcerias. E há um longo processo educativo, ao qual nos lançamos e estamos chamando de educação comunitária, ao invés de educação popular. Pois é preciso criar o corpo de comunidade, pautarmos nossas ações e decisões no bem comum, especialmente nos conflitos e crises que surgem, naturalmente, como em qualquer processo humano.

Por enquanto, vamos trabalhando na qualidade de nossos produtos, na qualidade de nossas rendas, aproveitando as técnicas desenvolvidas diferentemente pelas rendeiras. Vamos compreendendo como as cores se harmonizam, gerando diferentes efeitos. Vamos estudando formas de compor com as rendas acessórios, vestuários, buscando designers que possam ser nossos parceiros no desenvolvimento de peças que valorizem a delicadeza e beleza das rendas. Estamos preparando nosso primeiro mutirão para que as rendeiras se apropriem das diferentes etapas de produção e preparação dos itens para comercialização, com a compreensão da composição de preços, cadastramento e etiquetagem, entre outras ações que fazem parte do projeto como um todo.

Um item importante, parte de nossa formação comunitária, a autogestão vai sendo implementada.

A autogestão tem como mérito principal não a eficiência econômica (necessária em si), mas o desenvolvimento humano que proporciona aos praticantes. Participar das decisões e discussões do coletivo, ao qual se está associado, educa e conscientiza, tornando a pessoa mais realizada, autoconfiante e segura. É para isso que vale a pena se empenhar na economia solidária. (SINGER, 2002, p.21)

As ações não estão definidas completamente. O caminho também vai nos fazendo. E somos seres inacabados. Consequentemente, nossa civilização, formada por seres inacabados, é inacabada também. O que nos impede de, reconhecendo o mundo que vivemos, suas crises e decadências, e conhecendo propostas de alternativas que serão compostas por nossa própria experiência e saberes; 
tendo ações inclusivas, acolhendo-nos enquanto trabalhamos juntas na formação de um todo que tenha entre as emergências, cooperação, solidariedade, possibilidades de luta por uma vida digna e desenvolvimento pessoal, o que impede que possamos criar histórias nossas, novas e inovadoras?

Nada nos impede, é claro! Não temos garantias de que serão novas ou inovadoras. Mesmo assim, nos embrenhamos nos corredores do labirinto de nossa formação comunitária. E nos fins de semana nos sentamos na beira do rio, esse parceiro de jornada, junto a pescadores, aos "meninos da balsa" e fazemos rendas. $\mathrm{O}$ mundo e o tempo parecem que param um pouco. Eventualmente, o tempo das horas nos chama nas vozes de visitantes que se aproximam perguntando se é renda de bilros que fazemos. Conversamos, respondemos sobre as rendas, afirmando que não, elas não estão morrendo, pois estamos vivas. Pedem licença e tiram fotos: das rendas, das rendeiras, do rio. Pode ser que nossas histórias não sejam inovadoras e que nossos esforços sejam insuficientes para entrar no fluxo de uma nova civilização. O que podemos dizer, nós, 42 rendeiras de Águas Belas e redondezas? Que o mundo na beira do rio parece parar. O tempo parece parar. Mas nós, não. Afinal, temos trabalho para toda uma vida!

\section{Referências}

ACOSTA, Alberto. O Bem Viver: uma oportunidade para imaginar outros mundos. Autonomia Literária; Elefante: São Paulo, 2016.

ARNT, Rosamaria de Medeiros. Em busca de saberes para uma educação para a paz: Possibilidades transdisciplinares. In: PINTO, Magda; SCHERRE, Paula. Escolas ecossistêmicos e complexas: Olhares para além da fragmentação. Madrid: Global, 2018. E-book (200p).

Formação de professores e didática transdisciplinar: aproximações em foco. In: MORAES, Maria Cândida; BATALLOSO, Juan Miguel (orgs.) Complexidade e transdisciplinaridade em educação: teoria e prática docente. Rio de Janeiro: Wak, 2010.

Docência transdisciplinar: em busca de novos princípios para ressignificar a prática educacional. São Paulo: Programa de Pós-graduação em Educação: Currí- 
culo, PUC/SP. Tese de doutorado, 2007. Disponível em <http://www.sapientia. pucsp.br/tde_busca/arquivo.php?codArquivo=4742>. Acesso em 5 mar. 2015.

ARRUDA, Marcos. Educação para uma Economia do Amor: educação da práxis e economia solidária. Aparecida-SP: Ideias \& Letras, 2009.

BRANDÃO, Carlos R. Orar com o corpo: preceitos e preces para os gestos das horas dos dias. 2003. Disponível em http://www.apartilhadavida.com.br/wp-content/ uploads/2017/03/orar_corpo.pdf. Acesso em: 5 mar. 2020.

FREIRE, Paulo. Ação cultural para a liberdade. 8 ed,. Rio de Janeiro: Paz e Terra, 1982.

KAKÁ WERÁ. A arte do bem viver: conversa com Kaká Werá. YouTube. Canal Daniel Munduruku, 2019. Disponível em: https://youtu.be/wJS1YbT-Lhg. Acesso em: 5 mar. 2020. 10:15.

LARROSA, Jorge. Notas sobre a experiência e o saber de experiência. Revista Brasileira de Educação, ANPED, n. 19, jan-abr. 2002. Disponível em < http:/ /www. scielo.br/pdf/rbedu/n19/n19a02.pdf>. Acesso em 5 mar. 2020.

MATURANA, Humberto; VARELA, Francisco. A árvore do conbecimento. Campinas: Psy II, 1995.

MORIN, Edgar. A Via para o futuro da humanidade. Rio de Janeiro: Bertrand Brasil, 2013.

- O método 6: ética. Porto Alegre: Sulina, 2005.

- Os sete saberes necessários à educação do futuro. São Paulo: Cortez, 2000.

NARANJO, Javier. (Org) Casa das Estrelas: o universo pelo olhar das crianças. São Paulo: Planeta do Brasil, 2018.

NUNES, Débora. Incubação de empreendimentos de economia solidária: uma aplicação da pedagogia da participação. São Paulo: Annablume, 2009.

RAZETO, Luis. La crises de la civilización moderna y la creación de uma nunca civilización. Mimeo. 2016.

SINGER, Paul. Introdução à Economia Solidária. São Paulo: Fundação Perseu Abramo, 2002.

VASCONCELOS, Francisco A. de. Filosofia Ubuntu. In: LOGEION: Filosofia da informação, Rio de Janeiro, v. 3 n. 2, p. 100-112, mar./ ago. 2017. Disponível em < http://revista.ibict.br/fiinf/article/download/3841/3181>. Acesso em: 29 fev 2020. 